\title{
Effects of Holding Time During Artificial Aging Process on AA6061 to the Mechanical Properties
}

\author{
Atria Pradityana and Erik Kurniawan Widyantoro
}

\begin{abstract}
Materials that have been frequently used for automotive or construction equipment are Aluminum Alloys $(A A)$ 6061. Artificial aging is one of the processes to obtain optimal strength and hardness values. In this process, depending on the temperature and holding time. In this study, experiments have been carried out on the effects of holding time during the artificial aging process. Heating a solid solution at 300C for 1 hour is the first step. The holding time variations used are 1, 2, 3, 4, and 5 hours. Experiments have been made on impact strength, hardness values and microstructure. For hardness values decrease with increasing holding time. When holding time for 1 hour has a value of $80.8 \mathrm{HVN}$ while the holding time of 5 hours has a hardness value of $47.4 \mathrm{HVN}$. But in impact testing, the impact strength increases with increasing holding time. Both of these have been supported by microstructure observation data.
\end{abstract}

Keywords-AA6061, Temperature, Artificial Aging, Holding Time.

\section{INTRODUCTION}

The era where technology becomes more advanced makes various facilities such as industrial tools and components have better quality. It is aimed for humans as the users to use them more easily. In today's industrial world, material selection and manufacturing process of a product which is manufactured by a company should be in accordance with the function and the purpose of manufacturing the product. Therefore consumers would be satisfied to use the product because the product has the decent quality. In automotive and construction materials, AA Alloy (AA) 6061 is generally used. Specifically, weight reduction is an important part to enhance efficiency of the power of vehicles' engines. For the example is the application of AA Alloy on motor vehicles [1][2], and [3]. AA Alloy 6061 has has some profitable characteristics such as resistant to corrosion, able to be heated, good toughness, and also able to be welded well, there are lots of developed industries use this material as the main material in either tool designing's or constructions [1][2]. One of the methods which is able to be applied to obtain the AA with optimum hardness and strength is by age hardening. This research is to investigate the effect of the holding time for artificial aging on the microstructure and mechanical properties of $\mathrm{Al} 6061$.

Atria Pradityana and Erik Kurniawan Widyantoro are with Department of Industrial Mechanical Engineering, Institut Teknologi Sepuluh Nopember, Surabaya, 60111, Indonesia. E-mail: atriapradityana@gmail.com.

\section{EXPERIMENTAL PROCEDURES}

On this experiments, Aluminum Alloy 6061 was used with the material composition such as Zinc $0.05 \%$, Magnesium $1.0 \%$, Serium $0.19 \%$, Manganese $0.06 \%$, Iron $0.2 \%$, Silicon $0.64 \%$ and Titanium $0.07 \%$. Aluminum Alloy 6061 had mechanical properties that was Tensile Strength (ksi) at least 45.7 maximum 45.7, Yield Strength (ksi) minimum 42.1 maximum 42.6 and elongation $(\%)$ minimum 13.0 maximum 13.0.

The manufacture of the specimen was performed after the aluminum alloy has been purchased in accordance with predetermined size and shape. The solid solution treatment process conducted at $300^{\circ} \mathrm{C}$ for 1 hour is the first step to perform the test.

The quenching process in water was done because water was a suitable coolant for metal alloys that had low hardenability. After all work has been done quenching, then artificial aging process done with temperature $150^{\circ} \mathrm{C}$ using variation holding time 1, 2, 3, 4 and 5 hours. Each holding time variation used iteration of 3 test specimens. The specimen size $25 \times 10 \times 10$ (ASTM standard E18-03) was used for metallographic and hardness testing. However, on a specimen of hardness on one of the sides, points were used in which the distance between one point and another one was $5 \mathrm{~mm}$. On the impact testing, dimension specimen based on the standard ASTM E23 - 07a which refers to ASTM E23. The dimension was $55 \times 10 \times 10 \mathrm{~mm}$. It also had a notch with the dimension of $2 \mathrm{~mm}$, the radius of $0.25 \mathrm{~mm}$ and the angle of $45^{\circ}$. After all tests have been completed, the data collected for analysis, discussion and conclusions.

\section{RESULT AND DISCUSSION}

\section{A. Impact Testing}

Before impact testing was taken, AA 6061 was treated with artificial aging process. The variable changed was holding time and the temperature used was still $150^{\circ} \mathrm{C}$. The purpose of this impact testing was to find out about the influence of holding time on artificial aging process towards impact energy and strength. The testing used the machine charpy type HT-8041A. (Table 1)

To find out the value of impact energy and strength within the holding time variation, the specimen which had been treated with the aging process was impact tested. result of the impact testing on the testing objects which have been treated with aging process with the holding time variation 1 hour, 2 
hours, 3 hours, 4 hours, and 5 hours at $150^{\circ} \mathrm{C}$. Angles $(\beta)$ are the result of this impact testing. The detail of the impact energy and strength is shown in this chart.

TABLE 1.

PARAMETERS OF IMPACT TESTING

\begin{tabular}{ll}
\hline \hline \multicolumn{2}{c}{ Impact Testing Data of AA 6061 } \\
\hline Testing machine & $\begin{array}{l}\text { Impact testing machine charpy } \\
\text { type HT-8041A }\end{array}$ \\
& $131.7 \mathrm{~N}$ \\
$\begin{array}{l}\text { Weight of the pendulum }(\mathrm{W}) \\
\text { Distance of center of gravity } \\
\text { from thependulum to rotary }\end{array}$ & $0.60 \mathrm{~m}$ \\
axis $\mathrm{O}(\mathrm{L})$ & \\
Initial angle $(\alpha)$ & $140^{\circ}$ \\
Final angle $(\beta)$ & From the impact testing $\left(^{\circ}\right)$ \\
Cross-sectional area $(\mathrm{A})$ & From the impact testing $(\mathrm{mm} 2)$ \\
\hline \hline
\end{tabular}

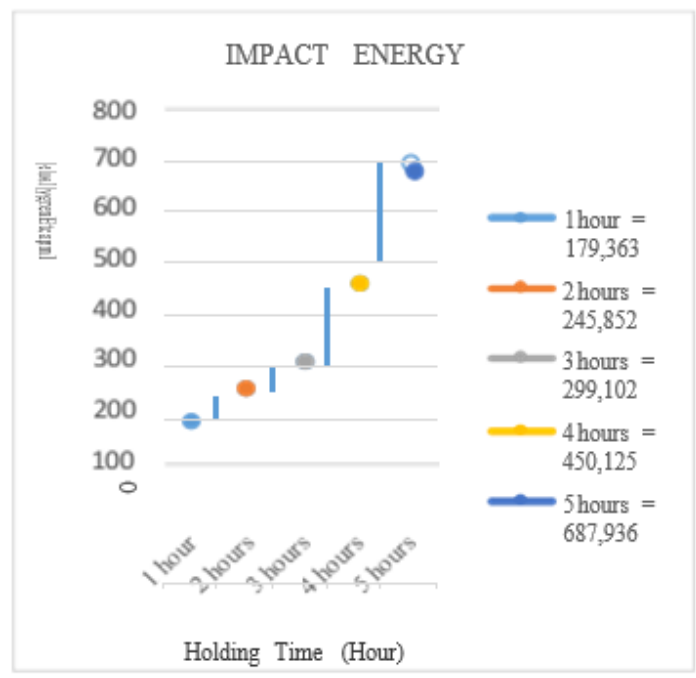

Figure 1. Impact energy after artificial aging process

From Figure 1, it could be seen that impact energy and strength kept increasing from the holding time of 1 hour to 5 hours. On the aging process, at the holding time of 1 hour it resulted the value of impact energy is 179,363 joule and the value of impact strength is 2,157 joule/ $\mathrm{mm}^{2}$. At the holding time of 2 hours, the value of impact energy increased to be 245,852 joule and the value of impact strength increased to be 3,040 joule $/ \mathrm{mm}^{2}$.

The increase of the value of impact energy and strength occurred every hour at the holding time of the material. When the holding time was increased to be 3 hours, the value of the impact energy also increased to be 299,102 joule and the impact strength increased to be 3,628 joule $/ \mathrm{mm}^{2}$. Holding time was increased to be 4 hours, the value of the impact energy also increased to be 450,125 joule and the impact strength increased to be 5,589 joule $/ \mathrm{mm} 2$. But at the holding time of 5 hours, the value of the impact energy increased significantly to be 687.936 joule and the impact strength increased to be 12.160 joule $/ \mathrm{mm}^{2}$.

From the result of the analysis, it found out that along with the increase of the holding time given to AA 6061, the increase of the value of impact energy and strength also occurred until the holding time of 5 hours. It occurred because at the holding time of the first to the fifth hour the microstructure of the AA had a deformation. In the aging process within the holding time variation from 1 hour until 5 hours the characteristics of the AA 6061 enhanced so that it could be resistant to shock voltages and the microstructure in the specimen diffused until it became homogeneous.

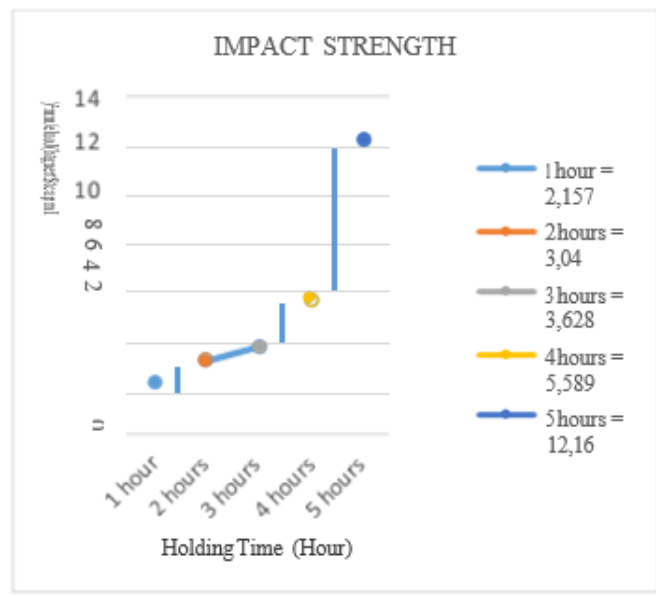

Figure 2. Impact strength after artificial aging process.

\section{B. Hardness Measurement}

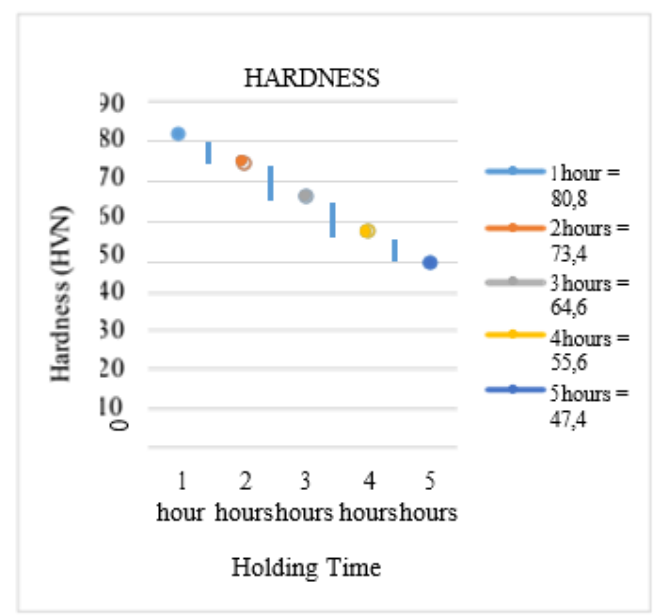

Figure 3. Hardness value after artificial aging process.

The purpose of hardness test is to find out how the value of hardness on aluminum 6061 with the variation of aging resistance that has been given. The result of hardness value on the testing objects that had been treated with aging process at $150^{\circ} \mathrm{C}$ within the holding time variation of 1 hour to 5 hours can be seen in the Figure 3.

From Figure 3 could be seen that the hardness value of Aluminium $6061 \mathrm{kept}$ decreasing along with the increase of the holding time from 1 hour to 5 hours long at $150^{\circ} \mathrm{C}$.

On the aging process at the holding time of 1 hour, it resulted the hardness value of $80.8 \mathrm{HVN}$. When the holding time was added to be 2 hours, the hardness value decreased to be $73.4 \mathrm{HVN}$. The decrease of the hardness value kept occurring along with the increasing holding time on the specimen that had been treated with aging process. It began from the holding time of 3 hours which resulted the hardness value of $64.6 \mathrm{HVN}, 4$ hours which resulted the hardness 
International Conference on Engineering, Advance Science and Industrial Application (ICETESIA) 2018

September 6-7 2018, Institut Teknologi Sepuluh Nopember, Surabaya, Indonesia

value of 55.6 HVN until at the fifth hour which resulted the hardness value of $47.4 \mathrm{HVN}$. The chart which shows the data resulted from the hardness testing on the Aluminium 6061 shows that holding time variation can influence hardness value. The more the holding time taken, the lesser the hardness of the Aluminium 6061. Aging process at $150^{\circ} \mathrm{C}$ within the holding time of 1 hour can cause hardening which has the zone phase [GP 2] or $\theta$. Phase if the holding time is added, so the phase will change into $\theta$ phase. The formation of the $\theta$ phase makes Aluminium less hard (softer).

\section{Surface Observation}

Microstructure was observed using optical microscope. Before it was observed, the specimen was etched using Keller's Reagent. The deformation of the microstructure is the qualitative data that supports the data of the value of the change of hardness and impact strength towards the change of the holding time in the aging process. Aluminium 6061 was heated with solution treatment at $300 \mathrm{o} C$ for 1 jam long then was quenched in water. After that, the testing object was aged with various holding time: 1 hour, 2 hours, 3 hours, 4 hours, 5 hours and the temperature was set to be fixed at $150^{\circ} \mathrm{C}$.

From the Figure 3 of the microstructure above, it is shown that the more the holding time taken on the aging process, the more the amount of the precipitates disappeared and the diffusion of the precipitates became more unorganized. Because the duration of the holding time caused the characteristic of the specimen to become homogeneous.

Heating treatment can cause microstructure of the specimen to have a deformation. Along with the increase of holding time given, the microstructure seemed to have a deformation. The deformation of the microstructure could be caused by the heating time taken, so it gave a chance for atoms to move. So that the form of the atoms became unorganized. By adding holding time on the aging process, the form of the precipitates became unorganized and duffused. Along with the increase of the holding time on the aging process was because of the formed GP Zone increasingly developed in size and amount. The increase of the holding time caused the precipitates to disappear and become unorganized. It causes the distance among the precipitate particles to be more distant. The distant precipitate showed that the material was homogeneous.

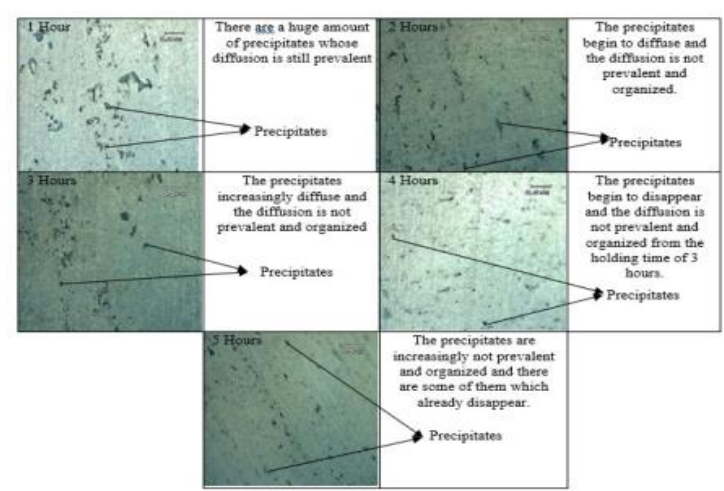

Figure 4. Microstructure after artificial aging.

\section{CONCLUSION}

From the result of the analysis and discussion about the impact, hardness, and metallographic testings' resulted data about the influence of holding time variation towards Aluminium 6061, it can be concluded that:

1. Most homogeneous specimen of the microstructure testing was formed at the holding time of the fifth hour.

2. The best of the impact strength is on the holding time 5 hours.

3. The specimen which was aged for 1 hour long is the specimen which has the best hardness value and the specimen which was aged for 5 hours is the specimen which has the lowest hardness value.

\section{ACKNOWLEDGMENT}

Thanks to Department of Mechanical Industrial Engineering Institute Teknologi Sepuluh Nopember for providing facilities in the work of this research.

\section{REFERENCES}

[1] K. Stobel, M. D. . Lay, and Mark A. Easton, "Effect of quench rate and natural ageing on the age hardening behaviour of AA alloy AA6060," Mater. Charact., vol. 111, pp. 43-52, 2016.

[2] I. Westermann, K. . Pedersen, and T. Borvik, "Work-hardening and ductility of artificially aged AA6060 aluminium alloy," Mech. Mater., vol. 97, pp. 100-117, 2016.

[3] A. D. Isadarea, B. Aremob, M. O. Adeoyec, O. J. Olawalec, and M. D. Shittuc, "Effect of Heat Treatment on Some Mechanical Properties of 7075 AA Alloy," J. Univ., 2013. 